\title{
Supramolecular Assembly of H-Bonded Side-Chain Polymers Containing Conjugated Pyridyl H-Acceptor Pendants and Various Low-Band-Gap H-Donor Dyes Bearing Cyanoacrylic Acid Groups for Organic Solar Cell Applications
}

\author{
TZUNG-CHI LIANG, ${ }^{1}$ I-HUNG CHIANG, ${ }^{1}$ PO-JEN YANG, ${ }^{1}$ DHANANJAY KEKUDA, ${ }^{2}$ \\ CHIH-WEI CHU, ${ }^{2,3}$ HONG-CHEU LIN ${ }^{1}$ \\ ${ }^{1}$ Department of Materials Science and Engineering, National Chiao Tung University, Hsinchu, \\ Taiwan, Republic of China \\ ${ }^{2}$ Research Center for Applied Sciences, Academia Sinica, Taipei, Taiwan, Republic of China \\ ${ }^{3}$ Department of Photonics, National Chiao Tung University, Hsinchu, Taiwan, Republic of China
}

Received 8 June 2009; accepted 14 July 2009

DOI: 10.1002 / pola.23643

Published online in Wiley InterScience (www.interscience.wiley.com).

\begin{abstract}
Novel supramolecular side-chain polymers were constructed by complexation of proton acceptor (H-acceptor) polymers, i.e., side-chain conjugated polymers P1-P2 containing pyridyl pendants, with low-band-gap proton donor (H-donor) dyes S1-S4 (bearing terminal cyanoacrylic acids) in a proper molar ratio. Besides unique mesomorphic properties confirmed by DSC and XRD results, the H-bonds of supramolecular side-chain structures formed by pyridyl $\mathrm{H}$-acceptors and cyanoacrylic acid H-donors were also confirmed by FTIR measurements. H-donor dyes S1-S4 in solid films exhibited broad absorption peaks located in the range of 471-490 $\mathrm{nm}$ with optical band-gaps of 1.99-2.14 eV. Furthermore, H-bonded polymer complexes P1/S1-P1/ S4 and P2/S1-P2/S4 exhibited broad absorption peaks in the range of 440-462 nm with optical band-gaps of 2.11-2.25 eV. Under $100 \mathrm{~mW} / \mathrm{cm}^{2}$ of AM 1.5 white-light illumination, the bulk heterojunction polymer solar cell (PSC) devices containing an active layer of H-bonded polymer complexes P1/S1-P1/S4 and P2/S1-P2/S4 (as electron donors) mixed with [6,6]-phenyl $\mathrm{C}_{61}$ butyric acid methyl ester (i.e., PCBM, as an electron acceptor) in the weight ratio of 1:1 were investigated. The PSC device containing H-bonded polymer complex P1/S3 mixed with PCBM (1:1 w/w) gave the best preliminary result with an overall power conversion efficiency (PCE) of $0.50 \%$, a short-circuit current of $3.17 \mathrm{~mA} / \mathrm{cm}^{2}$, an open-circuit voltage of $0.47 \mathrm{~V}$, and a fill factor of 34\%. (ㅇ 2009 Wiley Periodicals, Inc. J Polym Sci Part A: Polym Chem 47: 5998-6013, 2009

Keywords: dyes/pigments; H-bonded polymer complex; liquid-crystalline polymers (LCP); low-band-gap dye; polymer solar cell; supramolecular polymer; supramolecular structures
\end{abstract}

Additional Supporting Information may be found in the online version of this article. tw)

Correspondence to: H.-C. Lin (E-mail: linhc@cc.nctu.edu.

Journal of Polymer Science: Part A: Polymer Chemistry, Vol. 47, 5998-6013 (2009) (c) 2009 Wiley Periodicals, Inc.

\section{INTRODUCTION}

Self-assembled phenomena through molecular recognition between complementary constituents have been explored in various areas, such as the 
applications of biomaterials, liquid crystalline (LC) materials, and electro-optical materials. ${ }^{1-8}$ Not only innovative LC properties of novel supramolecules consisting of two counterparts can be generated through intermolecular hetero-hydrogen-bonding interactions, but also particular selfassembly of nanoscaled building blocks using noncovalent interactions (e.g., hydrogen bonding, acid/base proton transfer, and electrostatic forces) may be amplified into macroscopically observable phenomena. ${ }^{9}$ More recently, direct energy harvesting from sunlight by using photovoltaic cells (PVCs) has increasingly attracted intensified attention to utilize renewable energy of the nature, especially for the development of organic solar cells. ${ }^{10-12}$ Compared with inorganics (such as $\mathrm{Si}$ ), organic materials (especially polymers) have the benefits to be easily made into devices with light weight, large area, and flexible panels, so different concepts of solar cell architectures have been developed by organics, including blends of polymers ${ }^{13-20}$ and block copolymers ${ }^{21}$ with $[6,6]-$ phenyl $\mathrm{C}_{61}$ butyric acid methyl ester (i.e., PCBM, as an electron acceptor). Among the organic solar cell materials investigated so far, semiconducting conjugated polymers with electron donor-acceptor architectures are one of the most effective ways to build intramolecular charge transfer (ICT) interaction between the electron donor (D) and electron acceptor (A) segments. ${ }^{22-30}$ Conjugated D-A copolymers with strong ICT effects are promising materials for the development of high performance polymer-based PVCs due to the merits of narrow band-gaps, ${ }^{25-27}$ broad absorption bands extending into the near-infrared spectral range, efficient photoinduced charge transfer and separation, pronounced charge photogeneration and collection, and high mobility of ambipolar charge transport. ${ }^{28-30}$ Furthermore, different concepts of solar cell architectures, including the dye blends containing inorganics $\left(\mathrm{PCBM}, \mathrm{TiO}_{2}\right.$, and $\mathrm{ZnO}$ as electron acceptors $)^{31}$ and/or polymers, ${ }^{32-34}$ have been successfully progressed the efficiencies of the bulk heterojunction polymer solar cell (PSC) devices. However, due to the aggregations of the dyes originated from their strong $\pi-\pi$ interactions, the power conversion efficiency (PCE) values of PSC devices are limited by the dye contents in the polymer blends. Therefore, the $\mathrm{H}-$ bonded interactions of supramolecular polymers in this work can be introduced to reduce the aggregations of the low-band-gap organic dyes (as $\mathrm{H}$-donors), and thus, to improve the PCE values for the organic solar cell applications.
It is noticeable that the well-known electronwithdrawing unit would be an aryl-substituted cyano or nitro group, which has been widely utilized in organic solar cell materials, including metal-free dye sensitized solar cell (DSSC) materials. ${ }^{35}$ On account of the electron-rich sulfur and nitrogen atoms, especially in heterocyclic structures, polymers, and organic molecules ${ }^{36,37}$ containing carbazole, triphenylamine, and thiophene units as the electron-donating moieties have lately attracted considerable interests in the applications of light-emitting diodes, ${ }^{38,39}$ photovoltaic devices, ${ }^{40,41}$ and organic field effect transistors (OFETs). ${ }^{42}$ In the past years, various attempts have been made to increase the delocalization of $\pi$-electrons by constructing more coplanar conjugated systems to generate low-band-gap dyes. Another approach is to incorporate electronaccepting (A) units (e.g., cyano or nitro groups) with electron-donating (D) units (e.g., carbazole or triphenylamine groups) to produce low-bandgap dyes with resonance structures (i.e., D-A $\leftrightarrow$ $\left.\mathrm{D}^{+} \mathrm{A}^{-}\right){ }^{43,44}$ Recently, Lin and coworkers have introduced some novel conjugated spacers by inserting benzothiadiazole, benzoselenadiazole, and $1 H$-phenanthro[9,10- $d]$ imidazole segments into low-band-gap dyes (bearing D-A structures) for the applications of photovoltaic devices. ${ }^{45,46}$

To incorporate low-band-gap organic dyes (as $\mathrm{H}$-donors) into supramolecular polymers for organic solar cell applications, conjugated pyridyl $\mathrm{H}$ acceptors were integrated into the side-chain polymeric structures as the pendent groups rather than as small molecules (acting as luminescent chromophores) in our previous studies. ${ }^{47-50} \mathrm{As}$ shown in the schematic illustration of Figure 1, supramolecular side-chain polymers (i.e., Hbonded polymer complexes) were constructed by complexation of pyridyl $\mathrm{H}$-acceptor polymers, i.e., side-chain polymers P1-P2 containing conjugated pyridyl pendants, with low-band-gap $\mathrm{H}$-donor dyes S1-S4 (bearing terminal cyanoacrylic acids) in a molar ratio of 1:1 for pyridyl and acid units, which would have much more uptaken loads of photovoltaic dyes in the supramolecular polymeric structures (without phase separation) compared with the normal polymer blends. Our detailed investigations will prove that larger aggregations of the acid protected dyes occurred in the polymer blends due to the lack of supramolecular interactions, and a polymer blend of the conjugated $\mathrm{H}$ acceptor polymer $\mathbf{P 1}$ and the acid-protected dye S1P (refer Fig. S1 of the Supporting Information) illustrated an obvious reduction in the PCE value 


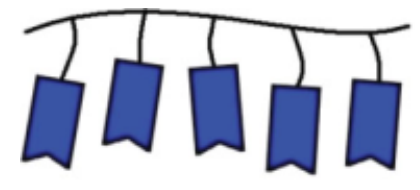

H-Acceptor Polymers

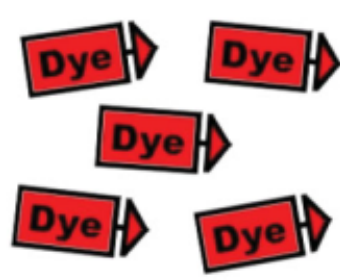

Side-Chain H-Bonded

Complexation

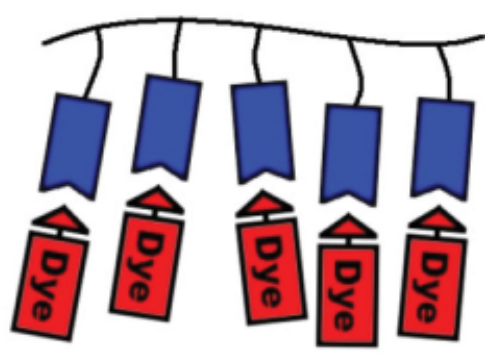

H-Bonded Complexes

\section{H-Donor Dyes}

Figure 1. Schematic illustration of complexation processes for H-bonded side-chain polymers. [Color figure can be viewed in the online issue, which is available at www.interscience.wiley.com.]

in contrast to the supramolecular analogue P1/S1. Different molar ratios of conjugated $\mathrm{H}$-acceptor monomer PBB (containing a pyridyl terminus) and hole-transporting monomer CAZ (bearing a carbazole unit) were copolymerized through free radical polymerization to obtain $\mathrm{H}$-acceptor polymers (P1 and P2). Both terminal carbazole or triphenylamine groups as electron-donating (D) units were in conjunction with cyanoacrylic acid groups as electron-accepting (A) units to yield lowband-gap H-donor dyes S1-S4, which were bridged through various numbers of fluorene, bithiazole, and thiophene units (refer Fig. 2). By incorporating side-chain conjugated $\mathrm{H}$-acceptor polymers with low-band-gap H-donor dyes, the LC and PVC properties of the supramolecular polymer complexes can be easily adjusted. The present investigation is mainly to explore the supramolecular structures of H-bonded side-chain polymers containing low-band-gap $\mathrm{H}$-donor dyes for the PSC applications. Therefore, the bulk heterojunction PSC devices containing an active layer of $\mathrm{H}$ bonded polymer complexes P1/S1-P1/S4 and P2/ S1-P2/S4 (as electron donors) mixed with PCBM (as an electron acceptor) were evaluated.

\section{EXPERIMENTAL}

\section{Materials}

Chemicals and solvents were reagent grades and purchased from Aldrich, ACROS, TCI, and Lan- caster Chemical. Dichloromathane and THF were distilled to keep anhydrous before use. The other chemicals were used without further purification. The synthetic routes of side-chain conjugated $\mathrm{H}-$ acceptor polymers P1 and P2 (as shown in Fig. 2) were reported in our previous publication. ${ }^{51}$ Synthesis and characterization of $\mathrm{H}$-donor dyes S1-S4 and their intermediates (refer Fig. 2) are described in the Supporting Information. The chemical structures for all products were confirmed by ${ }^{1} \mathrm{H}$ NMR spectroscopy and elemental analyses.

\section{Preparation of Supramolecular Polymer Complexes}

In all cases, all $\mathrm{H}$-donor dyes and $\mathrm{H}$-acceptor polymers (as shown in Fig. 2) were dissolved in THF to make a clear solution. After then, most of the solvents were evaporated under ambient conditions, which were followed by drying in a vacuum oven at $60{ }^{\circ} \mathrm{C}$ for several hours. The complexation of $\mathrm{H}$-donor acids and $\mathrm{H}$-acceptor polymers through hydrogen bonding was proceeded during the solvent evaporation. The H-bonded side-chain polymers of all $\mathrm{H}$-acceptor polymers complexed with H-donor dyes S1-S4 had the equal molar amount of pyridyl $\mathrm{H}$-acceptor and carboxylic acid $\mathrm{H}$-donor groups (in 1:1 $\mathrm{M}$ ratio) to form supramolecular polymer complexes (i.e., H-bonded side-chain polymers). 
$\mathrm{H}$-acceptor polymers<smiles>[Y]C(C)(C)CC(C)(CC(C)(C)C([X])(C)C(C)(CC(C)(C)C)C(=O)OCOc1ccc(C#Cc2cc(OC)c(/C=C/c3ccncc3)cc2OC)cc1)C(=O)OCn1c2ccccc2c2ccccc21</smiles>

$P 1: X=1, Y=0$

$P 2: X=1, Y=1$

\section{$\mathrm{H}$-donor dyes}

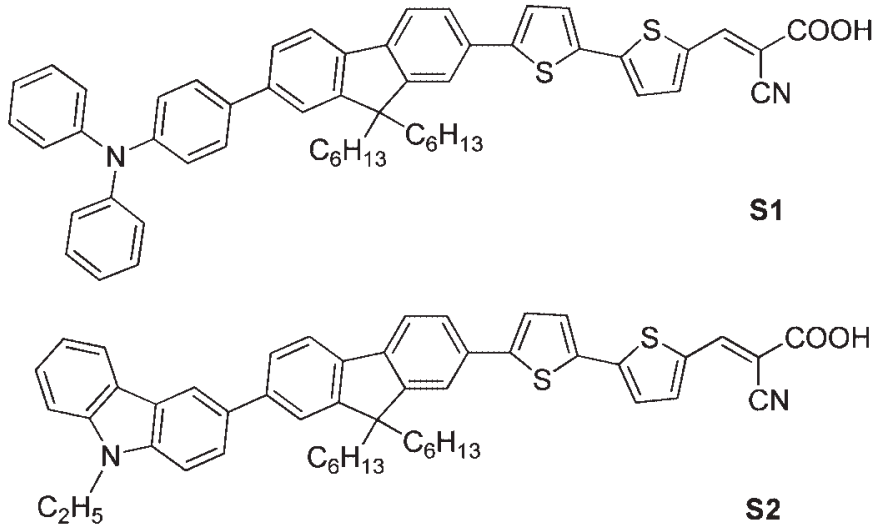

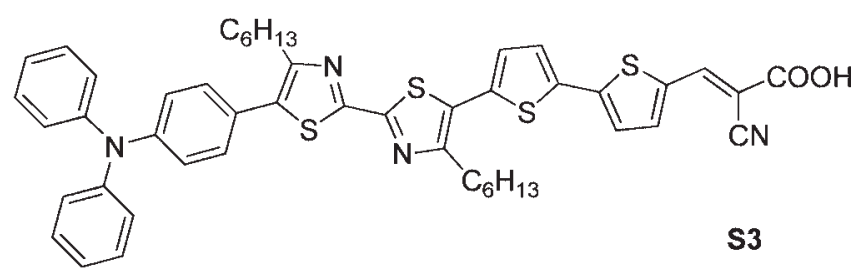

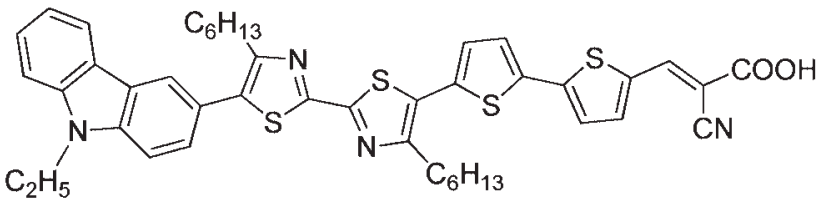

S4

Figure 2. H-acceptor polymers (P1 and P2) and H-donor dyes (S1-S4) used in the H-bonded polymer complexes (P1/S1-P1/S4 and P2/S1-P2/S4).

\section{Measurements and Characterization}

${ }^{1} \mathrm{H}$ NMR spectra were recorded on a Varian unity $300 \mathrm{MHz}$ spectrometer using $d$-DMSO as solvents. Elemental analyses were proceeded on a HERAEUS CHN-OS RAPID elemental analyzer. Fourier transform infrared (FT-IR) spectra were performed on a Nicolet 360 FT-IR spectrometer. The textures of mesophases were characterized by a polarizing optical microscope (POM, model: Leica DMLP) equipped with a hot stage. Temperatures and enthalpies of phase transitions were determined by differential scanning calorimetry (DSC, model: Perkin-Elmer Pyris 7) at a heating and cooling rate of $10{ }^{\circ} \mathrm{C} / \mathrm{min}$ under nitrogen. Thermogravimetric analyses (TGA) were conducted on a Du Pont Thermal Analyst 2100 system with a TGA 2950 thermogravimetric analyzer at a heating rate of $20^{\circ} \mathrm{C} / \mathrm{min}$ under nitrogen. Gel permeation chromatography (GPC) analyses were executed with a Water 1515 separations module using polystyrene as a standard and THF as an eluant. UV-visible absorption spectra were recorded in dilute THF solutions $\left(10^{-6} \mathrm{M}\right)$ on a HP G1103A spectrophotometer, and photoluminescence (PL) spectra were obtained on a Hitachi F-4500 spectrophotometer. Thin films of UV-vis and PL measurements were spin-coated on quartz substrates from THF solutions with a concentration of $1 \mathrm{wt} \%$. Cyclic voltammetry (CV) measurements were carried out using a BAS 100 electrochemical analyzer with a standard three-electrode electrochemical cell in a $0.1 \mathrm{M}$ tetrabutylammonium hexafluorophosphate $\left[(\mathrm{TBA}) \mathrm{PF}_{6}\right]$ solution (in acetonitrile) at room temperature with a scanning rate of $50 \mathrm{mV} / \mathrm{s}$. During the $\mathrm{CV}$ measurements, the solutions were purged with nitrogen for $30 \mathrm{~s}$. In each case, a carbon working electrode coated with a thin layer of copolymers, a platinum wire as the counter electrode, and a silver wire as the quasi-reference electrode were used, and $\mathrm{Ag} /$ $\mathrm{AgCl}$ (3 $\mathrm{M} \mathrm{KCl}$ ) electrode was served as a 
reference electrode for all potentials quoted herein. The redox couple of ferrocene/ferrocenium ion $\left(\mathrm{Fc} / \mathrm{Fc}^{+}\right)$was used as an external standard. The corresponding highest occupied molecular orbital (HOMO) and lowest unoccupied molecular orbital (LUMO) levels were calculated using $E_{\text {ox }} /$ onset and $E_{\text {red }} /$ onset for experiments in solid films of H-acceptor polymers (P1 and P2), H-donor dyes (S1-S4), and H-bonded polymer complexes (P1/S1-P1/S4 and P2/S1-P2/S4), which were performed by drop-casting films with a similar thickness from THF solutions $(\sim 5 \mathrm{mg} / \mathrm{mL})$. The LUMO level of PCBM used was in accordance with the literature datum. ${ }^{52}$ The onset potentials were determined from the intersections of two tangents drawn at the rising currents and background currents of the cyclic voltammetry (CV) measurements. Synchrotron powder X-ray diffraction (XRD) measurements were performed at beamline BL17A of the National Synchrotron Radiation Research Center (NSRRC) in Taiwan, where the X-ray wavelength used was $1.33,366 \AA$. XRD data were collected using imaging plates (IP, of an area $=20 \times 40 \mathrm{~cm}^{2}$ and a pixel resolution of 100) curved with a radius equivalent to the sample-to-image plate distance of $280 \mathrm{~mm}$, and the diffraction signals were accumulated for $3 \mathrm{~min}$. The powder samples were packed into a capillary tube and heated by a heat gun, where the temperature controller was programmable by a PC with a PID feed back system. The scattering angle theta values were calibrated by a mixture of silver behenate and silicon.

\section{Device Fabrication and Characterization of PSCs}

The PSC devices in this study were composed of an active layer of blended $\mathrm{H}$-bonded side-chain polymers (P1/S1-P1/S4 and P2/S1-P2/S4) mixed with $[6,6]$-phenyl $\mathrm{C}_{61}$ butyric acid methyl ester (i.e., PCBM) in solid films, which was sandwiched between a transparent indium tin oxide (ITO) anode and a metal cathode. Before device fabrication, ITO-coated glass substrates $\left(1.5 \times 1.5 \mathrm{~cm}^{2}\right)$ were ultrasonically cleaned in detergent, deionized water, acetone, and isopropyl alcohol. Afterward, the substrates were treated with UV ozone for $15 \mathrm{~min}$, and a layer of poly(ethylene dioxythiophene): polystyrenesulfonate (PEDOT:PSS, $\sim 30 \mathrm{~nm}$ ) was subsequently spin-coated onto the substrates. After baking at $130{ }^{\circ} \mathrm{C}$ for $1 \mathrm{~h}$, the substrates were transferred to a nitrogen-filled glovebox. The PSC devices were fabricated by spin-coating solutions of blended H-bonded poly- mer complexes:PCBM (with various weight ratios) onto the PEDOT:PSS modified substrates at $600 \mathrm{rpm}$ for $60 \mathrm{~s}(\sim 200 \mathrm{~nm})$, and placed in a covered glass Petri dish. Initially, the blended solutions were prepared by dissolving both $\mathrm{H}$-bonded polymer complexes (P1/S1-P1/S4 and P2/S1-P2/ S4) and PCBM (with a 1:1 weight ratio initially and then with various weight ratios for the optimum H-bonded polymer complex) in chlorobenzene $(20 \mathrm{mg} / 1 \mathrm{~mL})$, followed by continuous stirring for $12 \mathrm{~h}$ at $50{ }^{\circ} \mathrm{C}$. In the slow-growth approach, blended H-bonded polymer complexes in solid films were kept in the liquid phase after spin-coating by using the solvent (chlorobenzene) with a high boiling point. Finally, a calcium layer $(30 \mathrm{~nm})$ and a subsequent aluminum layer $(100 \mathrm{~nm})$ were thermally evaporated through a shadow mask at a pressure below $6 \times 10^{-6}$ Torr, and the active area of the device was $0.12 \mathrm{~cm}^{2}$. All PSC devices were prepared and measured under ambient conditions.

\section{RESULTS AND DISCUSSION}

\section{FT-IR Spectroscopy of H-Bonded Polymer Complexes}

All H-bonded side-chain polymers consisting of the appropriate molar ratio (fully $\mathrm{H}$-bonded complexes in a molar ratio of 1:1 for pyridyl and acid units) of $\mathrm{H}$-acceptor polymers (P1 and P2) and $\mathrm{H}$ donor dyes (S1-S4) were prepared by slow evaporation of THF solutions and followed by drying in vacuo. The formation of hydrogen bonding in supramolecular side-chain polymers containing H-donor dyes (S1-S4) was confirmed by FT-IR spectroscopy. As shown in Figure 3, IR spectra of $\mathrm{H}$-acceptor polymer P2, H-donor dye S1, and $\mathrm{H}$ bonded complex P2/S1 are compared to analyze the hydrogen bonds in the supramolecular structure of H-bonded polymer complex P2/S1. In contrast to the $\mathrm{O}-\mathrm{H}$ band of pure $\mathbf{S 1}$ at 2640 and $2510 \mathrm{~cm}^{-1}$, the weaker $\mathrm{O}-\mathrm{H}$ band observed at 2497 and $1902 \mathrm{~cm}^{-1}$ in H-bonded polymer complex P2/S1 is indicative of stronger hydrogen bonding between the pyridyl group of $\mathbf{P 2}$ and the carboxylic acid of $\mathbf{S 1}$ in the H-bonded complex. On the other hand, a $\mathrm{C}=\mathrm{O}$ stretching vibration appeared at $1722 \mathrm{~cm}^{-1}$ in H-bonded polymer complex P2/S1, which shows that the carbonyl group was in a less associated state than that in pure $\mathbf{S 1}$ with a weaker $\mathrm{C}=\mathrm{O}$ stretching vibration appeared at $1690 \mathrm{~cm}^{-1}$. Both results suggest that hydrogen bonds were formed between $\mathrm{H}$-acceptor 
polymer $\mathbf{P 2}$ and $\mathrm{H}$-donor dye $\mathbf{S 1}$ in the solid state of H-bonded polymer complex P2/S1. The other H-bonded polymer complexes also have the similar consequences of $\mathrm{H}$-bonding formation as the H-bonded complex demonstrated here. ${ }^{53}$ However, in comparison with $\mathrm{H}$-bonded polymer complex P1/S1, physical blend P1/S1P (without H-bonds) in Figure S2 (refer the Supporting Information) shows a weaker $\mathrm{C}=\mathrm{O}$ stretching vibration appeared at $1706 \mathrm{~cm}^{-1}$ for lack of $\mathrm{H}$-bonding interactions.

\section{Phase Behavior}

The phase transition temperatures of $\mathrm{H}$-acceptor polymers (P1 and P2), H-donor dyes (S1-S4), and H-bonded side-chain polymers (i.e., H-bonded polymer complexes P1/S1-P1/S4 and P2/S1-P2/ S4) are summarized in Table 1, which were determined by DSC (under nitrogen) and POM. The weight-average molecular weights $\left(M_{\mathrm{w}}\right)$ of $\mathrm{H}$ acceptor polymers $\mathbf{P 1}$ and $\mathbf{P 2}$ (determined by GPC) are $14,400 \mathrm{~g} / \mathrm{mol}(\mathrm{PDI}=1.72)$ and $38,100 \mathrm{~g} /$ mol (PDI $=3.24)$, respectively. The glass transition temperatures $\left(T_{\mathrm{g}}\right)$ of $\mathrm{H}$-acceptor polymers $\mathbf{P 1}$ and $\mathbf{P 2}$ are 63 and $88{ }^{\circ} \mathrm{C}$, respectively. ${ }^{51}$ To elucidate the $\mathrm{H}$-bonding effect of $\mathrm{H}$-bonded pendants on the thermal properties of supramolecular sidechain polymers, H-donor dyes S1-S4 were introduced to be incorporated with $\mathrm{H}$-acceptor side-chain polymers P1 and P2. As shown in Table 1, both series of H-bonded complexes containing $\mathrm{H}$-acceptor polymers P1 and P2 showed only a single glass transition, which suggests good miscibilities between H-donor dyes (i.e., S1S4) and H-acceptor polymers (i.e., P1 and P2).

Since no melting and crystallization transitions were observed in the DSC measurements, it suggests that these H-bonded complexes possess amorphous characteristics. However, the $T_{\mathrm{g}}$ values of the $\mathrm{H}$-bonded complexes are notably higher than those of their corresponding $\mathrm{H}$-acceptor polymers $\mathbf{P 1}$ and $\mathbf{P 2}$. The increases of $T_{\mathrm{g}}$ values in $\mathrm{H}-$ bonded complexes are probably due to the larger $\pi-\pi$ interactions originated from the increased rigid-rod lengths of the integrated $\mathrm{H}$-bonded pendants (containing both pyridyl $\mathrm{H}$-acceptor units and $\mathrm{H}$-donor dyes). In contrast to $\mathrm{H}$-acceptor homopolymer P1 and its H-bonded complexes, $\mathrm{H}$ acceptor copolymer P2 and its H-bonded complexes possessed higher $T_{\mathrm{g}}$ values due to the integration of more bulky and rigid $\mathbf{C A Z}$ components in copolymer P2. Comparing the H-bonded complexes containing fluorene-linked dyes (S1 and
S2) and bithiazole-linked dyes (S3 and S4), owing to the higher rigidity of bithiazole units in $\mathrm{H}$ donor dyes S3 and S4, the latter H-bonded complexes (P1-P2/S3 and P1-P2/S4) have higher $T_{\mathrm{g}}$ values than the former H-bonded complexes (P1P2/S1 and P1-P2/S2), respectively. This obviously indicates that the rigid bithiazole linkers will enhance the aggregation of the pendants in the H-bonded complexes effectively. In contrast to the H-bonded complexes (P1-P2/S1 and P1-P2/ S3) containing end-capping triphenylamine dyes (S1 and S3), owing to the higher rigidity and coplanarity of end-capping cabazole units in $\mathrm{H}$ donor dyes (S2 and $\mathbf{S 4}$ ), the analogous $\mathrm{H}$-bonded complexes (P1-P2/S2 and P1-P2/S4) containing end-capping cabazole dyes (S2 and S4) have higher $T_{\mathrm{g}}$ values.

The isotropization temperatures $\left(T_{\mathrm{i}}\right)$ have the similar trends as the glass transition temperatures $\left(T_{\mathrm{g}}\right)$ in H-bonded polymer complexes (P1/ S1-P1/S4 and P2/S1-P2/S4). Moreover, comparing analogous $\mathrm{H}$-bonded complexes consisting of the same H-donor dyes, H-bonded complexes containing $\mathrm{H}$-acceptor homopolymer P1 possess the higher isotropization temperatures $\left(T_{\mathrm{i}}\right)$ and the broader mesophasic ranges than those containing $\mathrm{H}$-acceptor copolymer P2. In addition, compared with H-bonded polymer complexes P1/S1 and P1/ S2 bearing fluorene-linked dyes (S1 and S2), Hbonded polymer complexes P1/S3 and P1/S4 bearing bithiazole-linked dyes (S3 and S4) have higher $T_{\mathrm{i}}$ values and broader mesophasic ranges. In general, the isotropization temperatures $\left(T_{\mathrm{i}}\right)$ and mesophasic ranges of $\mathrm{H}$-bonded side-chain polymers would be enhanced while the $\mathrm{H}$-bonded central cores are longer and more rigid.

As shown in Figure 4(a), the mesomorphic behavior of H-bonded polymer complex P2/S4 (cooling at $130{ }^{\circ} \mathrm{C}$ ) was confirmed as the nematic phase by the schlieren texture of POM, which was further elucidated by X-ray diffraction (XRD) measurements in Figure 4(b) that no sharp $d$ spacing values, i.e., no layered structures of the smectic phase, were observed in the XRD intensity against angle profiles of $\mathrm{H}$-bonded polymer complexes P1/S1 and $\mathbf{P 2 / S 4}$ at $130{ }^{\circ} \mathrm{C}$ (in the mesophasic range). According to the POM and XRD measurements, $\mathrm{H}$-acceptor homopolymer P1 and all H-bonded polymer complexes (P1/S1-P1/ S4 and P2/S1-P2/S4) in Table 1 were verified to possess the nematic phase, but $\mathrm{H}$-acceptor copolymer P2 bearing 50\% molar ratio of CAZ units did not possess any mesophase. Hence, the integration of CAZ units in copolymer P2 is detrimental 


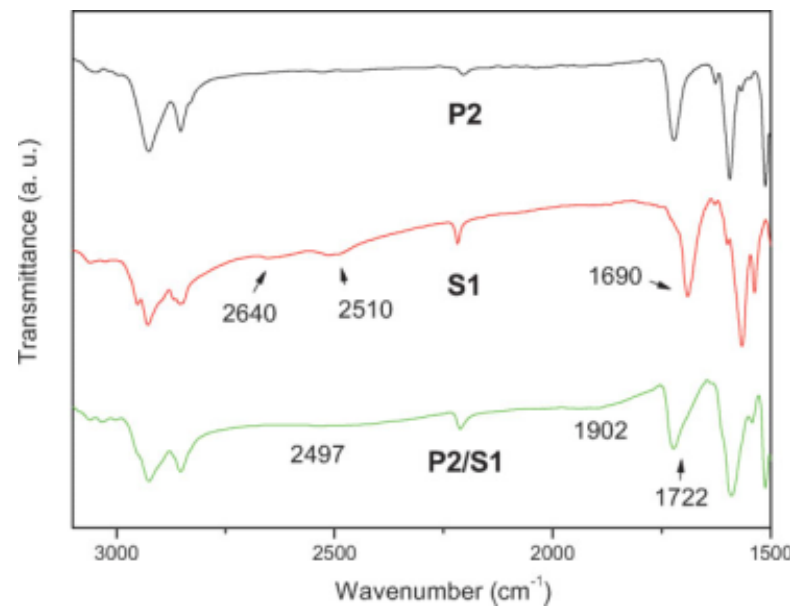

Figure 3. FTIR spectra of H-acceptor polymer P2, H-donor dye S1, and H-bonded polymer complex P2/ S1.

to the formation of the mesophase, which can be explained by that the $\mathbf{C A Z}$ units with nonmesomorphic property may dilute and hinder the molecular packing of the LC arrangements in copolymer P2. However, the nematic phase was introduced to the corresponding H-bonded polymer complexes (P2/S1-P2/S4) of copolymer P2 due to the extended H-bonded mesogens by combination of $\mathrm{H}$-acceptor pedants with $\mathrm{H}$-donor

Table 1. Thermal Properties of H-Acceptor Polymers (P1-P2), H-Donor Dyes (S1-S4), and H-Bonded Polymer Complexes (P1/S1-P1/S4 and P2/S1-P2/S4)

\begin{tabular}{cc}
\hline Compound & Phase Transitions $\left({ }^{\circ} \mathrm{C}\right)^{\mathrm{a}, \mathrm{b}}$ \\
\hline P1 & G 63 N $125^{\mathrm{c}} \mathrm{I}$ \\
P2 & G 88 K $110^{\mathrm{c}} \mathrm{I}$ \\
S1 & K $156(10.8) \mathrm{I}$ \\
S2 & K $163(13.4) \mathrm{I}$ \\
S3 & K $173(25.9) \mathrm{I}$ \\
S4 & K $180(26.3) \mathrm{I}$ \\
P1/S1 & G 87 N $151^{\mathrm{c}} \mathrm{I}$ \\
P1/S2 & G 89 N $155^{\mathrm{c}} \mathrm{I}$ \\
P1/S3 & G 96 N $167^{\mathrm{c}} \mathrm{I}$ \\
P1/S4 & G 99 N $172^{\mathrm{c}} \mathrm{I}$ \\
P2/S1 & G 96 N $141^{\mathrm{c}} \mathrm{I}$ \\
P2/S2 & G 98 N $147^{\mathrm{c}} \mathrm{I}$ \\
P2/S3 & G 104 N $156^{\mathrm{c}} \mathrm{I}$ \\
P2/S4 & G 105 N $162^{\mathrm{c}} \mathrm{I}$ \\
\hline
\end{tabular}

${ }^{\text {a }}$ Phase transition temperatures $\left({ }^{\circ} \mathrm{C}\right.$ ) and enthalpies (in parentheses, $\mathrm{kJ} / \mathrm{mol}$ ) were determined by DSC at a heating rate of $10^{\circ} \mathrm{C} / \mathrm{min}$.

${ }^{\mathrm{b}} \mathrm{G}$, glassy state; $\mathrm{K}$, crystalline; $\mathrm{N}$, nematic; I, isotropic.

${ }^{\mathrm{c}}$ Phase transition temperatures were obtained by POM and confirmed by XRD.

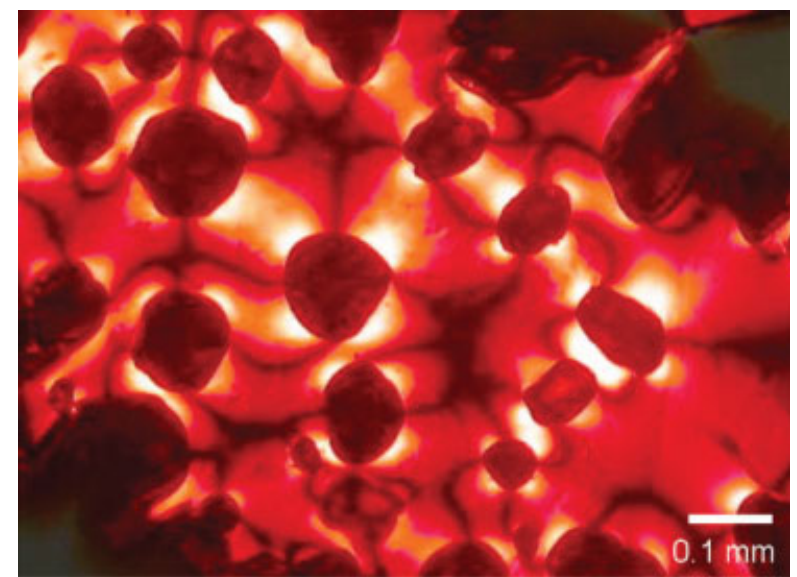

(a)

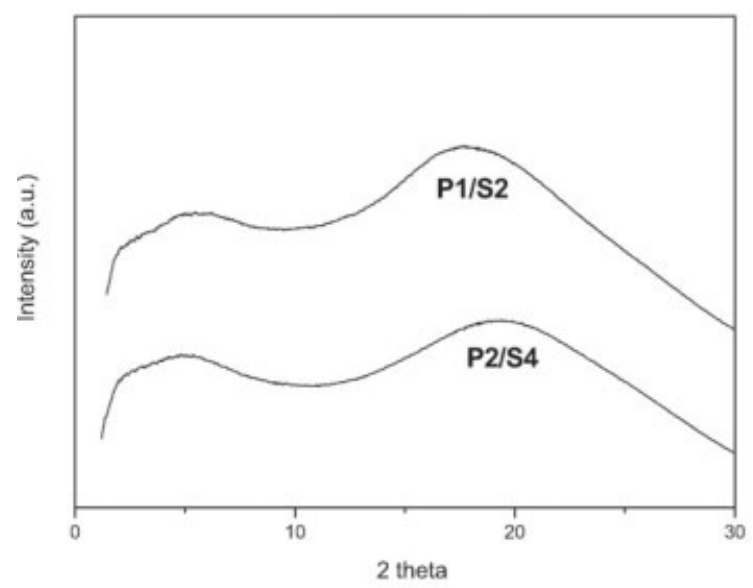

(b)

Figure 4. (a) Optical texture of the nematic phase in H-bonded polymer complex P2/S4 observed by $\mathrm{POM}$ at $130{ }^{\circ} \mathrm{C}$ (cooling) and (b) XRD intensity against angle profiles obtained from $\mathrm{H}$-bonded polymer complexes P1/S1 and P2/S4 at $130{ }^{\circ} \mathrm{C}$ (in the nematic phase).

dyes. Moreover, the mesophasic ranges and $T_{\mathrm{i}}$ values of the H-bonded polymer complexes (P2/S1P2/S4) containing copolymer P2 were apparently reduced by the $\mathbf{C A Z}$ units of $\mathrm{H}$-acceptor copolymer P2, which diluted and interfered the LC arrangements of the $\mathrm{H}$-bonded mesogens in their subsequent $\mathrm{H}$-bonded polymer complexes. However, acid-protected dye S1P and physical blend P1/S1P (without H-bonds) have lower phase transition temperatures (including the isotropization temperature $T_{\mathrm{i}}$ ) than $\mathrm{H}$-bonded polymer complex P1/S1 due to the dilution effect of the acid-protected dye S1P moieties in the physical blend P1/S1P (refer Table S1 of the Supporting Information).

Journal of Polymer Science: Part A: Polymer Chemistry DOI 10.1002/pola 
Table 2. Absorption and Photoluminescence Spectral Data of H-Acceptor Polymers (P1-P2), H-Donor Dyes (S1-S4), and H-Bonded Polymer Complexes (P1/S1-P1/S4 and P2/S1-P2/S4)

\begin{tabular}{cccc}
\hline Compound & $\begin{array}{c}\lambda_{\text {abs,sol }}{ }^{\mathrm{a}} \\
(\mathrm{nm})\end{array}$ & $\begin{array}{c}\lambda_{\text {abs,film }}{ }^{\mathrm{a}} \\
(\mathrm{nm})\end{array}$ & $\begin{array}{c}\lambda_{\mathrm{PL}, \mathrm{film}} \\
(\mathrm{nm})\end{array}$ \\
\hline P1 & 385 & 393 & 496 \\
P2 & 385 & 393 & 487 \\
S1 & 460 & 471 & 631 \\
S2 & 462 & 478 & 638 \\
S3 & 458 & 481 & 668 \\
S4 & 460 & 490 & 677 \\
P1/S1 & - & 440 & 614 \\
P1/S2 & - & 445 & 621 \\
P1/S3 & - & 462 & 640 \\
P1/S4 & - & 451 & 645 \\
P2/S1 & - & 440 & 611 \\
P2/S2 & - & 448 & 618 \\
P2/S3 & - & 457 & 638 \\
P2/S4 & - & 452 & 638 \\
\hline
\end{tabular}

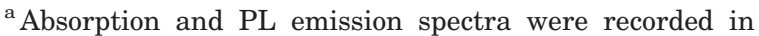
dilute THF solutions.

\section{Optical Properties}

The UV-visible absorption spectra of $\mathrm{H}$-acceptor polymers P1-P2 and H-donor dyes S1-S4 (in both THF solutions and solid films), and H-bonded polymer complexes P1/S1-P1/S4 and P2/S1-P2/ S4 (in solid films) are displayed in Figures 5 and 6 , and their photophysical properties are demonstrated in Table 2. The absorption energy bandgaps of H-bonded polymer complexes (P1/S1-P1/ S4 and P2/S1-P2/S4) could be easily tuned by the introduction of $\mathrm{H}$-donor dyes (S1-S4), and their absorption spectra covered broad wavelength ranges for both solutions and solid films. As shown in Figure 5, the maximum absorption wavelength $\left(\lambda_{\text {abs }}\right)$ of $\mathrm{H}$-acceptor polymers P1-P2 in THF solutions and solid films were 385 and $393 \mathrm{~nm}$, respectively, which were mainly contributed from the PBB units. The maximum absorption wavelength $\left(\lambda_{\text {abs }}\right)$ of H-donor dyes S1-S4 in THF solutions were in the range of 458-462 nm (in THF solutions) and 471-490 nm (in solid films). Because of the interchain association and $\pi-\pi$ stacking of these polymers and dyes in solids, the absorption spectra of all $\mathrm{H}$-acceptor polymers and $\mathrm{H}$-donor dyes in solid films were generally larger than those in dilute solutions (i.e., $8 \mathrm{~nm}$ red shifts in polymers and 11-30 $\mathrm{nm}$ red shifts in dyes). After complexation (in solid films as shown in Fig. 6), H-bonded polymer complexes P1/S1-
P1/S4 and P2/S1-P2/S4 displayed blue-shifted absorption peaks (at $440-462 \mathrm{~nm}$ ) in contrast to H-donor dyes S1-S4. The blue shifted absorption (blue shifted wavelength $\Delta \lambda_{\mathrm{abs}}=19-39 \mathrm{~nm}$ ) was due to the dilution effect of $\mathrm{H}$-acceptor polymers as solid solvents for dyes (as solutes) in solid $\mathrm{H}$ bonded polymer complexes. Compared with the $\mathrm{H}$-bonded complexes containing fluorene-linked dyes (S1 and S2), the corresponding H-bonded complexes containing bithiazole-linked dyes (S3 and S4) have longer absorption wavelengths and thus to have lower optical band-gaps, which were originated from the smaller optical band-gaps of bithiazole-linked dyes (S3 and S4) in solid films. Therefore, the H-bonded complexes containing bithiazole-linked dyes (S3 and S4) might have the gifts of lower optical band-gaps for further good performance in photovoltaic properties. However,

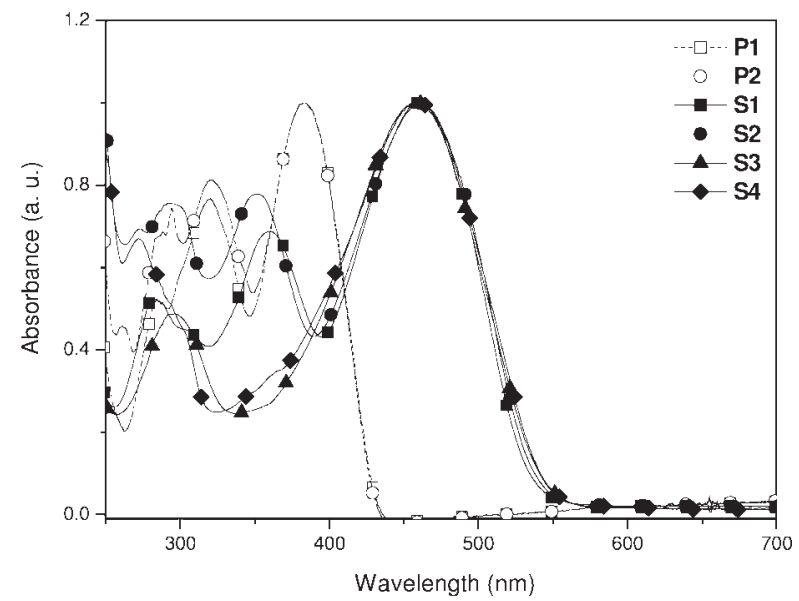

(a)

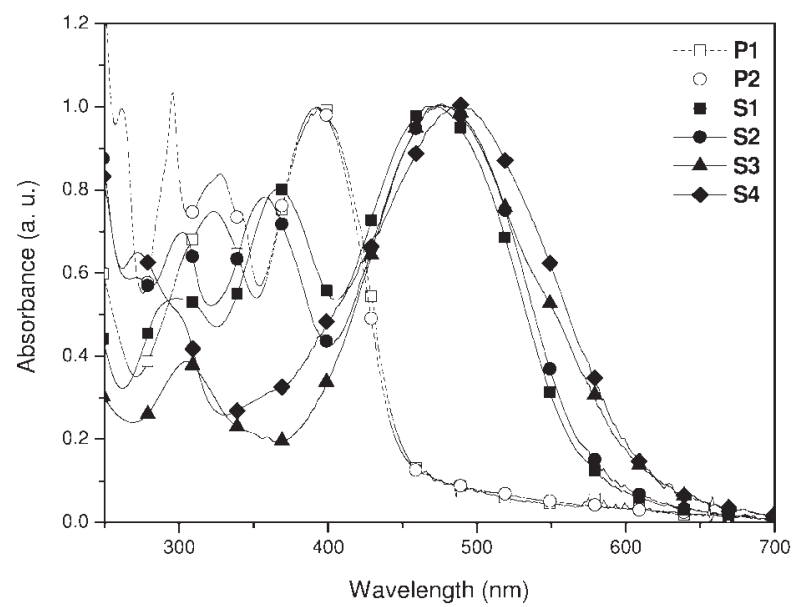

(b)

Figure 5. UV-visible absorption spectra of $\mathrm{H}$ acceptor polymers P1-P2 and H-donor dyes S1-S4 (a) in THF solutions and (b) in solid films. 


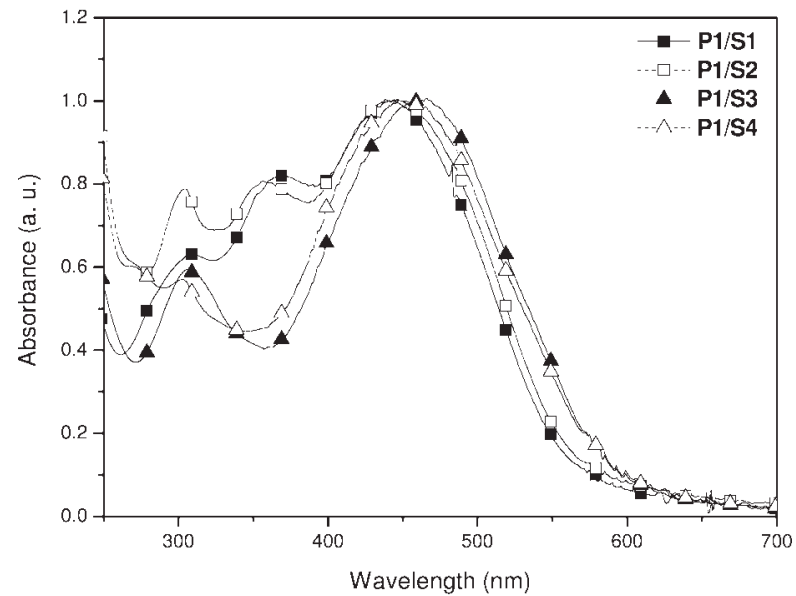

(a)

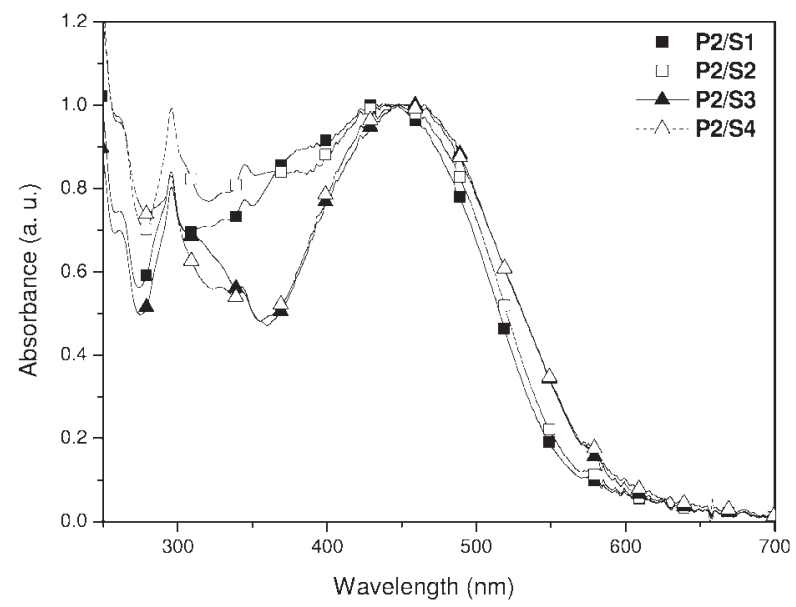

(b)

Figure 6. UV-visible absorption spectra of (a) Hbonded polymer complexes P1/S1-P1/S4 and (b) $\mathrm{H}$ bonded polymer complexes P2/S1-P2/S4 in solid films.

due to the lack of supramolecular interactions in polymer blend P1/S1P and a larger aggregation of the acid-protected dye S1P, a red-shifted (33 $\mathrm{nm})$ absorption in the solid film of polymer blend P1/S1P than that of H-bonded polymer complex P1/S1 was observed (refer Fig. S3 and Table S2 of the Supporting Information).

The photoluminescence (PL) spectra of $\mathrm{H}$ acceptor polymers P1-P2, H-donor dyes S1-S4, and H-bonded polymer complexes P1/S1-P1/S4 and P2/S1-P2/S4 (in solid films) are summarized in Table 1. Similar to the UV-visible absorption spectra, the PL emission wavelengths of $\mathrm{H}-$ bonded polymer complexes P1/S1-P1/S4 and P2/ S1-P2/S4 (at 611-645 nm) were all blue-shifted in contrast to those of H-donor dyes S1-S4 (at 631-677 nm). The PL emission spectra (in solid films) of the H-acceptor polymers P1 and P2 were dramatically quenched by adding $\mathrm{H}$-donor dyes S1-S4 in the H-bonded polymer complexes P1/S1P1/S4 and P2/S1-P2/S4. The corresponding optical quenching properties of these H-bonded complexes in solid films, including the broad optical absorptions and low optical band-gaps, proposed the potential applications in photovoltaic cells.

\section{Electrochemical Properties}

Narrow-band-gap H-bonded side-chain polymers were designed as donor-acceptor type materials by using $\mathrm{H}$-donor dyes containing electron-donating carbazole and triphenylamine moieties and electron-withdrawing cyano moieties. To understand the energy band structures of these new narrow-band-gap H-bonded polymer complexes for the PSC device application, the electronic states, i.e., highest occupied molecular orbital (HOMO) and lowest unoccupied molecular orbital (LUMO) levels, of the H-bonded side-chain polymers were investigated by the cyclic voltammetry (CV) measurements. The oxidation and reduction cyclic voltammograms of $\mathrm{H}$-bonded polymer complexes P1/S1-P1/S4 and P2/S1-P2/S4 in solid films are displayed in Figure 7. H-bonded polymer complexes P1/S1-P1/S4 and P2/S1-P2/S4 exhibited quasi-reversible (or reversible) oxidation and reduction peaks as evident from the areas and close proximity of the anodic and cathodic scans. The onset oxidation and reduction potentials (in solid films) of $\mathrm{H}$-acceptor polymers P1-P2, Hdonor dyes S1-S4, and H-bonded polymer complexes P1/S1-P1/S4 and P2/S1-P2/S4 are demonstrated Table $3 . \mathrm{Ag} / \mathrm{AgCl}$ was served as a reference electrode, and it was calibrated by ferrocene $\left(E_{\text {ferrocene }}^{1 / 2}=0.45 \mathrm{mV}\right.$ vs. $\left.\mathrm{Ag} / \mathrm{AgCl}\right)$. The HOMO and LUMO energy levels were estimated by the oxidation and reduction potentials from the reference energy level of ferrocene $(4.8 \mathrm{eV}$ below the vacuum level) according to the following equation: $E_{\text {HOMO/LUMO }}=\left[-\left(E_{\text {onset }}-0.45\right)-4.8\right] \mathrm{eV}$. According to the previous estimation, the HOMO and LUMO energy levels as well as the band-gap values directly measured from $\mathrm{CV}\left(E_{\mathrm{g}, \mathrm{cv}}\right)$ of all compounds are also summarized in Table 3.

As can be seen, all band-gap values of $E_{\mathrm{g}, \mathrm{cv}}$ had the analogous sequences as confirmed by the optical band-gap values observed from UV-vis spectra $\left(E_{\mathrm{g}, \mathrm{opt}}\right)$. By using the H-donor dyes with electron donor-acceptor effects, H-bonded polymer complexes P1/S1-P1/S4 and P2/S1-P2/S4 displayed narrower band-gaps ( $0.68 \mathrm{eV}$ smaller in $E_{\mathrm{g}, \mathrm{opt}}$ and 


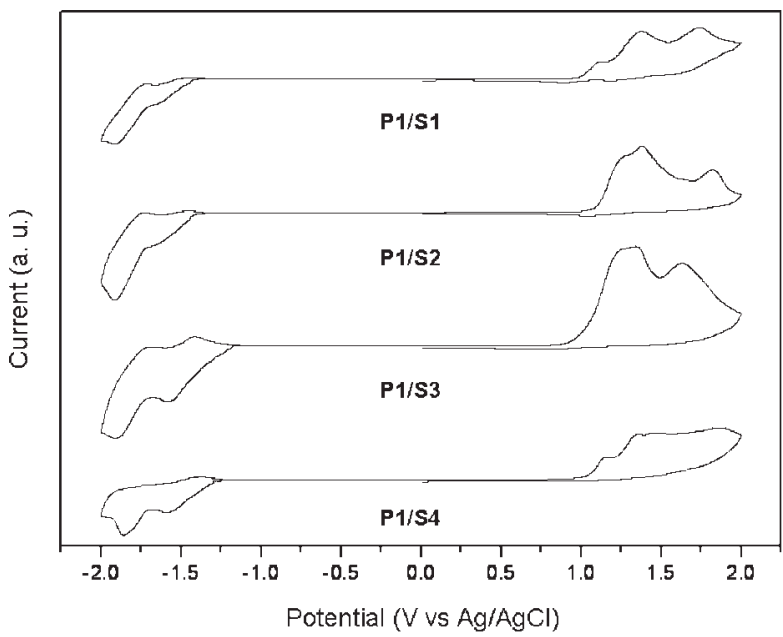

(a)

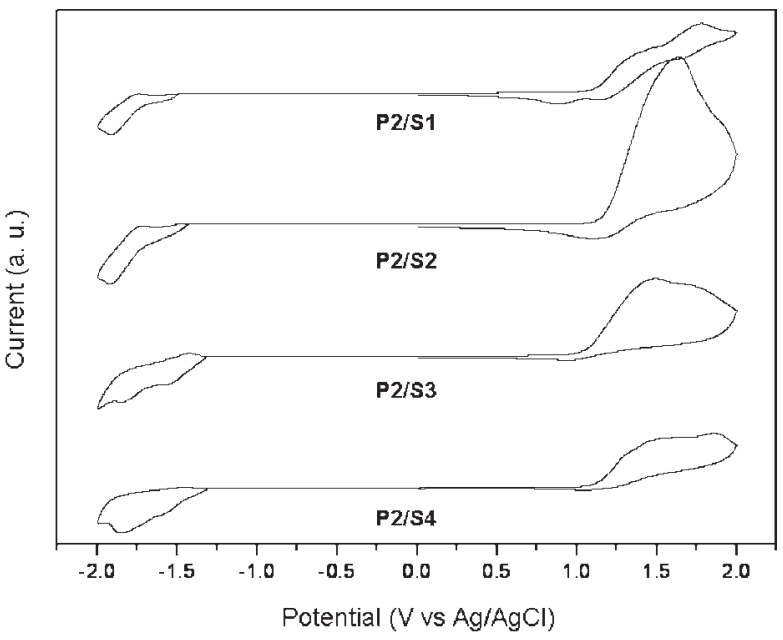

(b)

Figure 7. Cyclic voltammograms of H-bonded polymer complexes (a) P1/S1-P1/S4 and (b) P2/S1-P2/S4.

$0.51 \mathrm{eV}$ smaller in $\left.E_{\mathrm{g}, \mathrm{cv}}\right)$ compared to H-acceptor polymers P1-P2 (refer Table 3). However, due to the dilution results of $\mathrm{H}$-acceptor polymers P1P2, H-bonded polymer complexes P1/S1-P1/S4 and P2/S1-P2/S4 presented wider band-gaps in contrast to H-donor dyes S1-S4. It is worthwhile to note that the H-bonded complexes containing bithiazole-linked dyes (S3 and S4) have lower optical band-gaps $\left(E_{\mathrm{g}, \mathrm{cv}}\right.$ and $\left.E_{\mathrm{g}, \mathrm{opt}}\right)$ than the corresponding H-bonded complexes containing fluorene-linked dyes (S1 and S2), which was originated from the smaller optical band-gaps of bithiazole-linked dyes (S3 and S4) in solid films. Compared with $\mathrm{H}$-acceptor polymers P1-P2 and H-donor dyes S1-S4, the medium HOMO and LUMO energy levels of H-bonded polymer complexes (P1/S1-P1/S4 and P2/S1-P2/S4) could be adjusted. Therefore, the electrochemical reductions of $\mathrm{H}$-bonded complexes showed similar LUMO energy levels at about $(-2.92)-(-3.04) \mathrm{eV}$, which represented to possess high electron affinities and also make these H-bonded complexes suitable donors for electron injection and transporting to PCBM acceptors (with $0.71-0.83 \mathrm{eV}$ offsets in LUMO levels regarding PCBM with a LUMO level of $-3.75 \mathrm{eV}$ as shown in Fig. 8) ${ }^{23(\mathrm{~b})}$ for the polymeric bulk heterojunction solar cell devices. On the basis of the oxidation potential data, the introduction of electron-withdrawing cyano groups in $\mathrm{H}$-donor dyes to the $\mathrm{H}$-bonded complexes can induce the decreases of HOMO energy levels at about $(-5.36)-(-5.52) \mathrm{eV}$, which represented to possess high hole transporting properties and also make these $\mathrm{H}$-bonded complexes suitable donors for hole injection and transporting to PEDOT:PSS layer and then to ITO electrode (with $0.06-0.22 \mathrm{eV}$ offsets in HOMO levels regarding PEDOT:PSS layer with a HOMO level of $-5.3 \mathrm{eV}$ as illustrated in Fig. $8)^{23(\mathrm{~b})}$ for the polymeric bulk heterojunction solar cell devices. ${ }^{54}$ Thus, the electrochemical properties of H-bonded complexes could be adjusted by introducing electron-withdrawing cyano groups and electron-donating amine groups of $\mathrm{H}$-donor dyes to the H-bonded complexes, which can reduce the HOMO energy levels and increase the LUMO energy levels of the H-bonded side-chain polymers, and thus, to have narrower band-gaps.

\section{Photovoltaic Cell Properties}

The design and syntheses of the H-bonded sidechain polymers P1/S1-P1/S4 and P2/S1-P2/S4 is to utilize new narrow band-gap H-donor dyes selfassembled with side-chain conjugated $\mathrm{H}$-acceptor polymers into supramolecular polymeric structures for the PSC applications. To investigate the potential use of H-bonded complexes in PSCs, bulk heterojunction PSC devices with a configuration of ITO/PEDOT:PSS/H-bonded polymer complexes:PCBM $(1: 1 \mathrm{w} / \mathrm{w}) / \mathrm{Ca} / \mathrm{Al}$ were fabricated from an active layer where $\mathrm{H}$-bonded complexes were blended with a complementary fullerenebased electron acceptor PCBM in a weight ratio of 1:1 (w/w) initially (and later followed with various weight ratios for the optimum H-bonded polymer complex). The PSC devices were measured under AM 1.5 illumination for a calibrated solar simulator with an intensity of $100 \mathrm{~mW} / \mathrm{cm}^{2}$. The preliminarily photovoltaic properties are summarized in Table 4 , and the typical $I-V$ characteristics of all 
Table 3. Electrochemical Potentials and Energy Levels of H-Acceptor Polymers (P1-P2), H-Donor Dyes (S1-S4), and H-Bonded Polymer Complexes (P1/S1-P1/S4 and P2/S1-P2/S4)

\begin{tabular}{cccccccc}
\hline Compound & $\lambda_{\text {onset,abs }}(\mathrm{nm})^{\mathrm{a}}$ & $E_{\mathrm{g}, \mathrm{opt}}(\mathrm{eV})^{\mathrm{a}}$ & $E_{\text {ox }}(\mathrm{eV})^{\mathrm{b}}$ & $\mathrm{HOMO}(\mathrm{eV})^{\mathrm{c}}$ & $E_{\mathrm{re}}(\mathrm{eV})^{\mathrm{b}}$ & $\mathrm{LUMO}_{(\mathrm{eV})^{\mathrm{c}}} E_{\mathrm{g}, \mathrm{cv}}(\mathrm{eV})$ \\
\hline P1 & 445 & 2.79 & 1.18 & -5.53 & -1.67 & -2.68 & 2.85 \\
P2 & 445 & 2.79 & 1.17 & -5.52 & -1.65 & -2.70 & 2.82 \\
S1 & 580 & 2.14 & 0.96 & -5.31 & -1.47 & -2.88 & 2.43 \\
S2 & 587 & 2.11 & 1.04 & -5.39 & -1.40 & -2.95 & 2.44 \\
S3 & 622 & 1.99 & 1.00 & -5.35 & -1.33 & -3.02 & 2.33 \\
S4 & 620 & 2.00 & 1.03 & -5.38 & -1.30 & -3.05 & 2.33 \\
P1/S1 & 552 & 2.25 & 1.01 & -5.36 & -1.43 & -2.92 & 2.44 \\
P1/S2 & 558 & 2.22 & 1.09 & -5.44 & -1.40 & -2.95 & 2.49 \\
P1/S3 & 584 & 2.12 & 1.01 & -5.36 & -1.33 & -3.02 & 2.34 \\
P1/S4 & 586 & 2.11 & 1.04 & -5.39 & -1.32 & -3.03 & 2.36 \\
P2/S1 & 554 & 2.24 & 1.09 & -5.44 & -1.42 & -2.93 & 2.51 \\
P2/S2 & 557 & 2.23 & 1.17 & -5.52 & -1.37 & -2.98 & 2.54 \\
P2/S3 & 581 & 2.13 & 1.03 & -5.38 & -1.31 & -3.04 & 2.34 \\
P2/S4 & 589 & 2.11 & 1.08 & -5.43 & -1.35 & -3.00 & 2.42 \\
\hline
\end{tabular}

${ }^{\text {a }}$ Absorption wavelengths obtained in solid films and optical band-gaps calculated from the equation of $E_{\mathrm{g}, \mathrm{opt}}=1240 / \lambda_{\text {edge }}$

${ }^{\mathrm{b}}$ Onset oxidation and reduction potentials.

${ }^{\mathrm{c}} E_{\mathrm{HOMO}} / E_{\mathrm{LUMO}}=\left[-\left(E_{\text {onset }}-0.45\right)-4.8\right] \mathrm{eV}$ where $0.45 \mathrm{~V}$ is the value of ferrocene versus $\mathrm{Ag} / \mathrm{Ag}^{+}$and $4.8 \mathrm{eV}$ is the energy level of ferrocene below the vacuum.

PSC devices are shown in Figure 9. Under the white-light illumination, the short circuit current density $\left(I_{\mathrm{sc}}\right)$, open circuit voltage $\left(V_{\text {oc }}\right)$, fill factor $(\mathrm{FF})$, and PCE values of the PSC devices composed of $\mathrm{H}$-bonded polymer complexes were in the range of $0.42-3.17 \mathrm{~mA} / \mathrm{cm}^{2}, 0.38-0.59 \mathrm{~V}$, and $24-$ $34 \%, 0.06-0.50 \%$, respectively.

The photovoltaic properties of the PSC devices containing H-bonded polymer complexes P1/S1P1/S4 and P2/S1-P2/S4 were dependent on the solubility and film-forming quality of the $\mathrm{H}$ bonded complexes. However, the PCE values of $\mathrm{H}-$ bonded complexes P2/S1-P2/S4 containing Hacceptor copolymer $\mathbf{P 2}$ were apparently smaller than those of P1/S1-P1/S4, respectively, because the 1:1 $\mathrm{M}$ ratio of pyridyl and acid units of fully H-bonded P2/S1-P2/S4 would reduce the content of low-band-gap dyes complexed with $\mathrm{H}$-acceptor copolymer P2 bearing $50 \mathrm{~mol} \%$ of pyridyl units. As shown in Table 4, both series of H-bonded complexes (P1/S1-P1/S4 and P2/S1-P2/S4) containing electron donors of end-capping triphenylamine dyes (S1 and S3) had better PCE values than those containing end-capping carbazole dyes

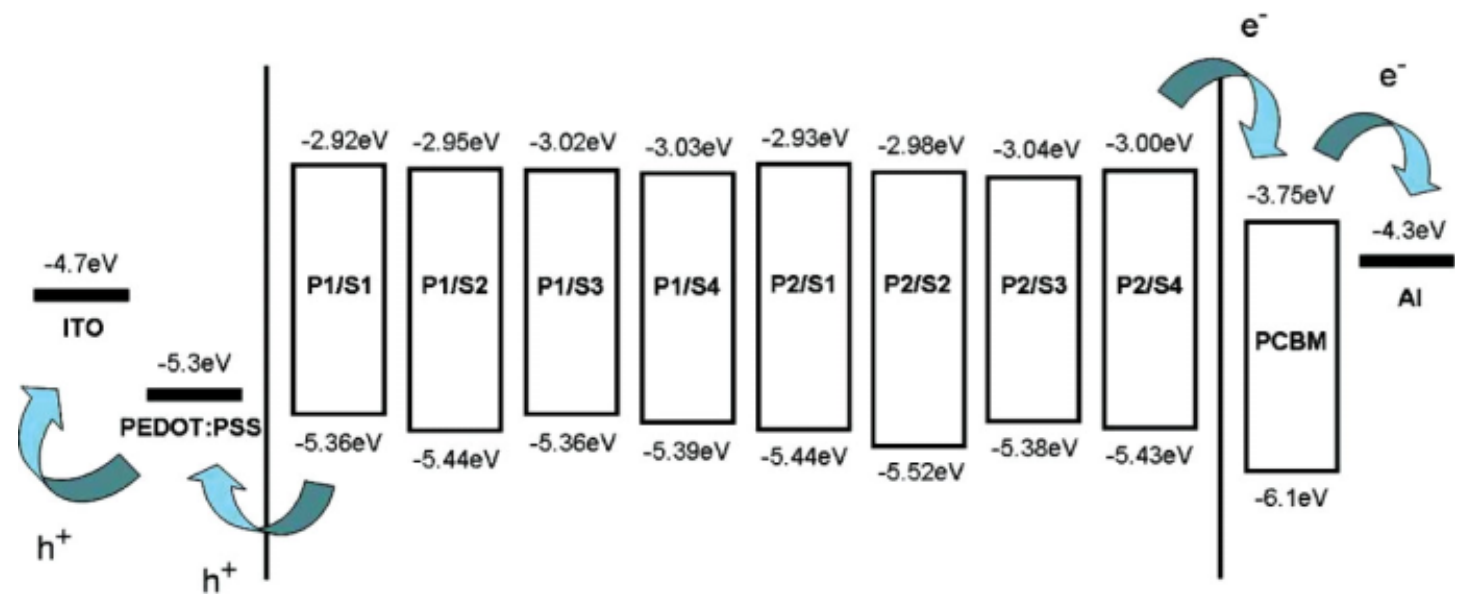

Figure 8. Energy band diagram with HOMO/LUMO levels of H-bonded polymer complexes P1/S1-P1/S4 (as electron donors) and PCBM (as an electron acceptor) in relation to the work functions of ITO, PEDOT:PSS, and Al (HOMO value of PCBM was obtained from ref. 23). [Color figure can be viewed in the online issue, which is available at www.interscience.wiley.com.] 
Table 4. Photovoltaic Properties of PSC Devices Containing an Active Layer of H-Bonded Polymer Complexes:PCBM = 1:1 (w/w) with a Device Configuration of ITO/PEDOT:PSS/H-Bonded Polymer Complexes:PCBM/Ca/Al ${ }^{\mathrm{a}}$

\begin{tabular}{|c|c|c|c|c|}
\hline $\begin{array}{c}\text { Active Layer }^{\mathrm{b}} \\
\text { H-Bonded } \\
\text { Complexes: } \\
\text { PCBM }\end{array}$ & $\begin{array}{l}V_{\mathrm{oc}} \\
(\mathrm{V})\end{array}$ & $\begin{array}{c}I_{\mathrm{sc}} \\
\left(\mathrm{mA} / \mathrm{cm}^{2}\right)\end{array}$ & $\begin{array}{l}\mathrm{FF} \\
(\%)\end{array}$ & $\begin{array}{c}\mathrm{PCE} \\
(\%)\end{array}$ \\
\hline $\mathbf{P} 1 / \mathbf{S 1}^{\mathrm{c}}$ & 0.59 & 1.67 & 27 & 0.28 \\
\hline P1/S2 & 0.54 & 1.72 & 28 & 0.26 \\
\hline P1/S3 & 0.47 & 3.17 & 34 & 0.50 \\
\hline P1/S4 & 0.43 & 1.70 & 26 & 0.19 \\
\hline P2/S1 & 0.58 & 0.95 & 24 & 0.13 \\
\hline P2/S2 & 0.53 & 0.42 & 27 & 0.06 \\
\hline P2/S3 & 0.51 & 2.29 & 28 & 0.32 \\
\hline P2/S4 & 0.38 & 0.73 & 24 & 0.07 \\
\hline
\end{tabular}

${ }^{\text {a }}$ Measured under AM 1.5 irradiation, $100 \mathrm{~mW} / \mathrm{cm}^{2}$.

${ }^{\mathrm{b}}$ H-Bonded Polymer Complexes:PCBM = with the fixed weight ratio of $1: 1(\mathrm{w} / \mathrm{w})$.

${ }^{\mathrm{c}}$ PCE of P1/S1P: $0.16 \%$.

(S2 and S4), respectively. It might be due to the larger aggregations of end-capping carbazole dyes (S2 and S4) to reduce the PCE values, which were confirmed by the redder shifted maximum absorption wavelengths $\left(\Delta \lambda_{\text {abs }}\right.$ $\left.=\lambda_{\text {abs,solid }}-\lambda_{\text {abs,solution }}\right)$ in solid films of end-capping carbazole dyes $\left(\Delta \lambda_{\text {abs }}=16 \mathrm{~nm}\right.$ for $\mathbf{S 2}$ and $\Delta \lambda_{\text {abs }}=30 \mathrm{~nm}$ for $\left.\mathbf{S 4}\right)$ than those of end-capping triphenylamine dyes $\left(\Delta \lambda_{\text {abs }}=11 \mathrm{~nm}\right.$ for $\mathbf{S 1}$ and $\Delta \lambda_{\text {abs }}=23 \mathrm{~nm}$ for S3), respectively. Among the PSC devices containing H-bonded polymer complexes, those composed of H-donor dye S3, i.e., P1/S3 and P2/S3, had the best photovoltaic performance with enhanced $I_{\mathrm{sc}}$ values in the corresponding H-bonded complexes P1/S1-P1/S4 and P2/S1-P2/S4, respectively, which might be due to the promoted solubility and better film-forming capability of S3. Ideally, the $I_{\mathrm{sc}}$ values were determined by the product of the photoinduced charge carrier densities and the charge carrier mobilities within the organic semiconductors. ${ }^{11}$ Thus, it can be recognized that the better results of $I_{\mathrm{sc}}$ and FF in the PSC device containing P1/S3 and P2/S3 were obtained likely due to the well-balanced charge flow and less significant recombination $\operatorname{loss}^{24,55}$ originated from the highly order structural packing of alkyl side chains. However, the relatively low $I_{\mathrm{sc}}$ and $\mathrm{FF}$ values in the PSC devices containing P1/S4 and P2/S4 were poorly understood at this time, but it might be related to the largest aggregation of $\mathbf{S 4}$ (with the reddest shifted maximum absorption wavelengths in solid, $\Delta \lambda_{\text {abs }}=30 \mathrm{~nm}$ ) and geminate charge recombination at the interface due to stable chargetransfer states, which limited the values of the photocurrents. ${ }^{56}$ Though $V_{\text {oc }}$ values were related to the differences between the HOMO energy levels of the polymers and the LUMO energy levels of the acceptors,${ }^{57}$ but it was not noticeably varied among the PSC devices containing H-bonded complexes. In addition, the $I-V$ curves and photovoltaic properties of dyes S1-S4 without complexation with the polymers are illustrated in Figure S4 and Table S3 (refer the Supporting Information), which can be compared with the PCE values

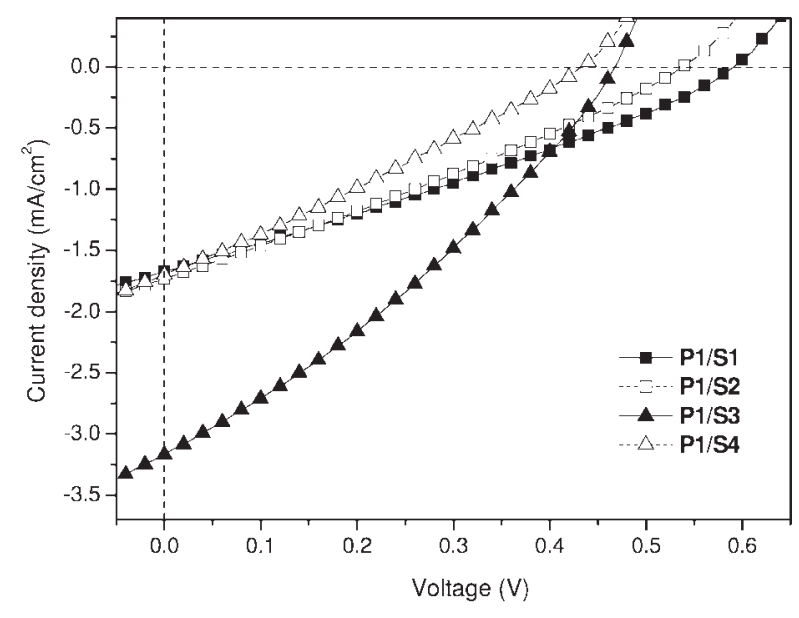

(a)

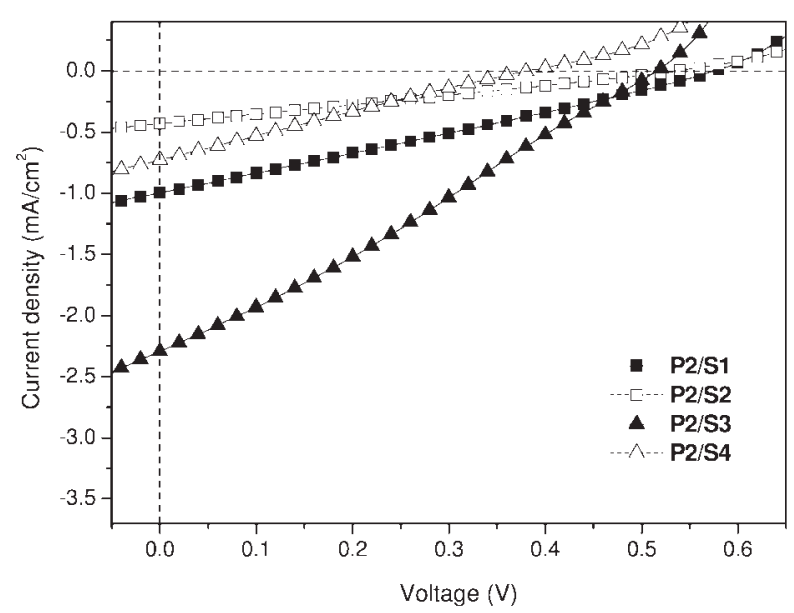

(b)

Figure 9. $I-V$ curves (under simulated AM 1.5 solar irradiation) dependencies of PSC devices with an active layer of blended (a) H-bonded polymer complexes P1/S1-P1/S4:PCBM (1:1 w/w) and (b) H-bonded polymer complexes P2/S1-P2/S4:PCBM (1:1 w/w). 
shown in Table 4. In general, the H-bonded polymer complexes containing $\mathrm{H}$-acceptor polymers (P1 and P2) have higher PCE values for the organic solar cells, even though the corresponding dye contents of S1-S4:PCBM = 1:1 (w/w) without complexation with polymers in the active layer were almost doubled than those of $\mathrm{H}$-bonded polymer complexes (H-bonded polymer complexes:PCBM = 1:1 w/w). Hence, H-acceptor polymers (P1 and P2) do really improve and facilitate the fabrication of solar cells. To demonstrate the contribution of supramolecular structures in $\mathrm{H}$ bonded polymer complexes, one more PSC device containing an active layer of physical blend P1/ S1P (without H-bonds) has been fabricated to compare their photovoltaic properties with those of H-bonded polymer complex P1/S1. Compared with H-bonded polymer complex P1/S1 (PCE = 0.28\%), physical blend P1/S1P (without H-bonds) has a smaller PCE value (0.16\%) in Figure S4 and Table S5 (refer the Supporting Information). The larger aggregations of the acid-protected dye S1P occurred in the polymer blend P1/S1P due to the lack of H-bonding interactions, which also can be confirmed by the red-shifted ( $33 \mathrm{~nm}$ ) absorption of polymer blend P1/S1P in contrast to that of $\mathrm{H}-$ bonded polymer complex P1/S1 in solid films.

Since the best performance of PSC device (with the highest PCE value in Table 4) was fabricated by the blend of H-bonded polymer complex P1/ S3:PCBM $(1: 1 \mathrm{w} / \mathrm{w})$, the current-voltage characteristics of PSC devices as a function of the weight ratio in H-bonded complex and PCBM were surveyed, and their photovoltaic properties are

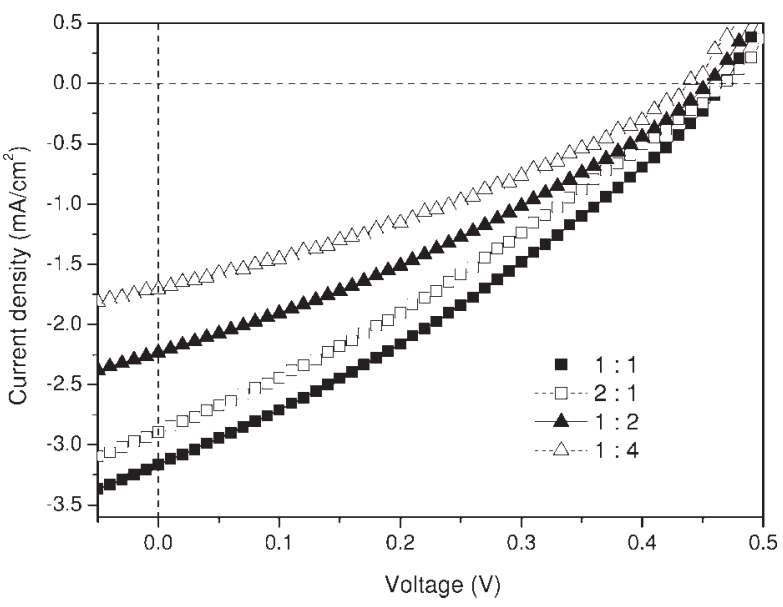

Figure 10. $I-V$ curves of PSC devices containing an active layer of H-bonded polymer complex P1/ S3:PCBM (w/w) with different weight ratios under simulated AM 1.5 solar irradiation.
Table 5. Photovoltaic Parameters for BulkHeterojunction PSC Devices Containing Different Weight Ratios of Blended H-Bonded Polymer Complex P1/S3:PCBM ${ }^{\mathrm{a}}$

\begin{tabular}{ccccc}
$\begin{array}{c}\text { Weight } \\
\text { Ratios of } \\
\text { Blended } \\
\begin{array}{c}\text { H-Bonded } \\
\text { Complex }\end{array}\end{array}$ & $\begin{array}{c} \\
V_{\text {oc }}\end{array}$ & $\begin{array}{c}I_{\text {sc }} \\
\left(\mathrm{mA} / \mathrm{cm}^{2}\right)\end{array}$ & $\begin{array}{c}\mathrm{FF} \\
(\%)\end{array}$ & $\begin{array}{c}\mathrm{PCE} \\
(\%)\end{array}$ \\
\hline P1/S3:PCBM & $(\mathrm{V})$ & 2.90 & 20 & 0.40 \\
$2: 1$ & 0.46 & 3.17 & 34 & 0.50 \\
$1: 1$ & 0.47 & 2.23 & 30 & 0.28 \\
$1: 2$ & 0.45 & 1.70 & 33 & 0.25 \\
$1: 4$ & 0.44 & & & \\
\hline
\end{tabular}

${ }^{\text {a }} \mathrm{PSC}$ devices with the configuration of ITO/PEDOT:PSS/ H-Bonded Polymer Complex P1/S3:PCBM/Ca/Al containing an active blended layer composed of various weight ratios of H-bonded polymer complex P1/S3 and PCBM were measured under AM 1.5 irradiation, $100 \mathrm{~mW} / \mathrm{cm}^{2}$.

shown in Figure 10 and Table 5. The optimum photovoltaic performance with the maximum PCE value of $0.50 \%\left(I_{\mathrm{sc}}=3.17 \mathrm{~mA} / \mathrm{cm}^{2}, V_{\mathrm{oc}}=0.47\right.$ $\mathrm{V}, \mathrm{FF}=34 \%)$ was obtained in the PSC device having a weight ratio of P1/S3:PCBM $=1: 1$. Using lower weight ratios of $\mathrm{PCBM}$ in blended $\mathrm{H}$-bonded polymer complex P1/S3:PCBM (2:1 w/w) led to the reduction in $I_{\mathrm{sc}}$ values due to the inefficient charge separation and electron transporting properties by the possibly increased aggregation of $\mathrm{H}$ bonded complex P1/S3, resulting in the lower PCE results. ${ }^{58}$ However, loading larger weight ratios of $\mathrm{PCBM}$ in blended $\mathrm{H}$-bonded polymer complex P1/S3:PCBM (1:2 and 1:4 w/w) also reduced the $I_{\mathrm{sc}}$ and $\mathrm{PCE}$ values, which could be probably attributed to the increased aggregation of PCBM so as to affect the separation of charges. Moreover, an unbalanced charge transporting property would be introduced due to the large PCBM ratio. Hence, both $I_{\mathrm{sc}}$ and PCE values decreased with larger PCBM molar ratios of 1:2 and 1:4 (w/w) because of the two reasons described here. ${ }^{59}$ Overall, the PSC device fabricated by H-bonded polymer complexes P1/ S3:PCBM $(1: 1 \mathrm{w} / \mathrm{w})$ reached the highest PCE of $0.50 \%$, with a short circuit current density $\left(I_{\mathrm{sc}}\right)$ of $3.17 \mathrm{~mA} / \mathrm{cm}^{2}$, an open circuit voltage $\left(V_{\mathrm{oc}}\right)$ of 0.47 $\mathrm{V}$, and a fill factor $(\mathrm{FF})$ of 0.34 .

\section{CONCLUSIONS}

In conclusion, novel supramolecular side-chain polymers (i.e., H-bonded polymer complexes) were 
constructed by complexation of pyridyl $\mathrm{H}$-acceptor polymers with low-band-gap $\mathrm{H}$-donor dyes in a molar ratio of 1:1 for pyridyl and acid units, which would have much more uptaken loads of photovoltaic dyes in the supramolecular polymeric structures compared with the normal polymer blends. Because of the lack of supramolecular interactions, the larger aggregations of the acid-protected dyes occurred in the polymer blends, and thus a polymer blend (without H-bonds) containing conjugated $\mathrm{H}$-acceptor polymer P1 and acidprotected dye S1P illustrated an obvious reduction in the PCE value in contrast to the supramolecular analogue P1/S1. H-donor dyes (S1-S4) and $\mathrm{H}$-acceptor polymers (P1 and P2) were utilized to control the mesomorphic, photophysical, and photovoltaic properties effectively by the concept of supramolecular architecture. The supramolecular architectures of $\mathrm{H}$-bonded side-chain polymers were also confirmed by FTIR and XRD measurements. The nematic phase was observed by the introduction of various $\mathrm{H}$-donor dyes and $\mathrm{H}$-acceptor polymers with corresponding supramolecular side-chain structures. In addition, compared with H-donor dyes, the optical properties demonstrated that blue-shifted absorptions occurred in these H-bonded complexes as the $\mathrm{H}$ donor dyes were complexed with $\mathrm{H}$-acceptor polymers. Thus, the electrochemical properties of $\mathrm{H}$-bonded complexes were adjusted by introducing electron-withdrawing cyano groups and electrondonating amine groups of $\mathrm{H}$-donor dyes to the $\mathrm{H}$ bonded complexes, which could reduce the HOMO energy levels and increase the LUMO energy levels of the H-bonded side-chain polymers, and thus, to have narrower band-gaps than $\mathrm{H}$ acceptor polymers. Because of the reduced content of low-band-gap dyes complexed with $\mathrm{H}$-acceptor copolymer P2, the PCE values of H-bonded complexes P2/S1-P2/S4 containing H-acceptor copolymer P2 were apparently smaller than those of P1/S1-P1/S4, respectively. Preliminary PSC devices based on these $\mathrm{H}$-bonded polymer complex P1/S3 blended with PCBM acceptors (1:1 w/w) had the PCE up to $0.50 \%$, which gave the best performance with the values of $I_{\mathrm{sc}}=3.17 \mathrm{~mA} / \mathrm{cm}^{2}$, $V_{\text {oc }}=0.47 \mathrm{~V}$, and $\mathrm{FF}=34 \%$.

The authors are grateful to the National Center for High-performance Computing for computer time and facilities. The powder XRD measurements are supported by beamline BL17A (charged by J.-J. Lee) of the National Synchrotron Radiation Research Center (NSRRC), in Taiwan. The financial supports of this project provided by the National Science Council of Taiwan
(ROC) through NSC 97-2113M-009-006-MY2, National Chiao Tung University through 97W807, and Energy and Environmental Laboratories (charged by C.-C. Yang) in Industrial Technology Research Institute (ITRI) are acknowledged.

\section{REFERENCES AND NOTES}

1. Ikkala, O.; Brinke, G. T. Science 2002, 295, 24072409.

2. Stupp, S. I.; Son, S.; Lin, H. C.; Li, L. S. Science 1993, 259, 59-63.

3. Kato, T.; Mizoshita, N.; Kishimoto, K. Angew Chem Int Ed 2006, 45, 38-68.

4. (a) Broeren, M. A. C.; Linhardt, J. G.; Malda, H.; de Waal, B. F. M.; Versteegen, R. M.; Meijer, J. T.; Löwik, D. W. P. M.; van Hest, J. C. M.; van Genderen, M. H. P.; Meijer, E. W. J Polym Sci Part A: Polym Chem 2005, 43, 6431-6437; (b) Montarnal, D.; Cordier, P.; Soulié-Ziakovic, C.; Tournilhac, F.; Leibler, L. J Polym Sci Part A: Polym Chem 2008, 46, 7925-7936; (c) Vellis, P. D.; Mikroyannidis, J. A.; Lo, C. N.; Hsu, C. S. J Polym Sci Part A: Polym Chem 2008, 46, 7702-7712; (d) Cheng, C. C.; Huang, C. F.; Yen, Y. C.; Chang, F. C. J Polym Sci Part A: Polym Chem 2008, 46, 6416-6424; (e) Coluccini, C.; Metrangolo, P.; Parachini, M.; Pasini, D.; Resnati, G.; Righetti, P. J Polym Sci Part A: Polym Chem 2008, 46, 5202-5213; (f) Bosman, A. W.; Sijbesma, R. P. J Polym Sci Part A: Polym Chem 2008, 46, 3877-3885; (g) Aamer, K. A.; Tew, G. N. J Polym Sci Part A: Polym Chem 2007, 45, 1109-1121; (h) Stefopoulos, A. A.; Pefkianakis, E. K.; Papagelis, K.; Andreopoulou, A. K.; Kallitsis, J. K. J Polym Sci Part A: Polym Chem 2009, 47, 2551-2559.

5. Pisula, W.; Tomović, Ž.; Wegner, M.; Graf, R.; Pouderoijen, M. J.; Meijer, E. W.; Schenning, A. P. H. J. J Mater Chem 2008, 18, 2968-2977.

6. (a) Vera, F.; Almuzara, C.; Orera, I.; Barberá, J.; Oriol, L.; Serrano, J. L.; Sierra, T. J Polym Sci Part A: Polym Chem 2008, 46, 5528-5541; (b) Fustin, C. A.; Guillet, P.; Misner, M. J.; Russell, T. P.; Schubert, U. S.; Gohy, J. F. J Polym Sci Part A: Polym Chem 2008, 46, 4719-4724; (c) Guillet, P.; Fustin, C. A.; Lohmeijer, B. G. G.; Schubert, U. S.; Gohy, J. F. Macromolecules 2006, 39, 54845488; (d) Fustin, C. A.; Guillet, P.; Schubert, U. S.; Gohy, J. F. Adv Mater 2007, 19, 1665-1673; (d) Burke, K. A.; Sivakova, S.; McKenzie, B. M.; Mather, P. T.; Rowan, S. J. J Polym Sci Part A: Polym Chem 2006, 44, 5049-5059.

7. Kato, T.; Matsuoka, T.; Nishii, M.; Kamikawa, Y.; Kanie, K.; Nishimura, T.; Yashima, E.; Ujiie, S. Angew Chem Int Ed 2004, 43, 1969-1972. 
8. Mamlouk, H.; Heinrich, B.; Bourgogne, C.; Donnio, B.; Guillon, D.; Felder-Flesch, D. J Mater Chem 2007, 17, 2199-2205.

9. (a) Wanunu, M.; Popovitz-Biro, R.; Cohen, H.; Vaskevich, A.; Rubinstein, I. J Am Chem Soc 2005, 127, 9207-9215; (b) Obare, S. O.; Hollowell, R. E.; Murphy, C. J. Langmuir 2002, 18, 1040710410.

10. Winder, N. S.; Saridifti, N. S. J Mater Chem 2004, 14, 1077-1086.

11. Günes, S.; Neugebauer, H.; Sariciftci, N. S. Chem Rev 2007, 107, 1324-1338.

12. Yang, X.; Loos, J. Macromolecules 2007, 40, 13531362.

13. Granstrom, M.; Petritsch, K.; Arias, A. C.; Lux, A.; Andersson, M. R.; Friend, R. H. Nature 1998, 395, 257-260.

14. Halls, J. J. M.; Walsh, C. A.; Greenham, N. C.; Marseglia, E. A.; Friend, R. H.; Moratti, S. C.; Holmes, A. B. Nature 1995, 376, 498-500.

15. Kietzke, T.; Hörhold, H.-H.; Neher, D. Chem Mater 2005, 17, 6532-6537.

16. Breeze, A. J.; Salomon, A.; Ginley, D. S.; Gregg, B. A.; Tillmann, H.; Hörhold, H.-H. Appl Phys Lett 2002, 81, 3085-3087.

17. Yu, G.; Gao, J.; Hummelen, J. C. Science 1995, 270, 1789-1791.

18. Brabec, C. J.; Sariciftci, N. S.; Hummelen, J. C. Adv Funct Mater 2001, 11, 15-26.

19. Al-Ibrahima, M.; Rotha, H. K.; Zhokhavetsb, U. Sol Energy Mater Sol Cells 2005, 85, 13-20.

20. Ma, W.; Yang, C.; Gong, X.; Lee, K.; Heeger, A. J. Adv Funct Mater 2005, 15, 1617-1622.

21. Lindner, S. M.; Hüttner, S.; Chiche, A.; Thelakkat, M.; Krausch, G. Angew Chem Int Ed 2006, 45, 3364-3368.

22. Peet, J.; Kim, J. Y.; Coates, N. E.; Ma, W. L.; Moses, D.; Heeger, A. J.; Bazan, G. C. Nat Mater 2007, 6, 497-500.

23. Mülhlbacher, D.; Scharber, M.; Morana, M.; Zhu, Z.; Waller, D.; Gaudiana, R.; Brabec, C. Adv Mater 2006, 18, 2884-2889.

24. Zhu, Z.; Waller, D.; Gaudiana, R.; Morana, M.; Mülhlbacher, D.; Scharber, M.; Brabec, C. Macromolecules 2007, 40, 1981-1986.

25. Huo, L.; He, C.; Han, M.; Zhou, E.; Li, Y. F. J Polym Sci Part A: Polym Chem 2007, 45, 38613871.

26. Colladet, K.; Fourier, S.; Cleij, T. J.; Lutsen, L.; Gelan, J.; Vanderzande, D. Macromolecules 2007, 40, 65-72.

27. Shahid, M.; Ashraf, R. S.; Klemm, E.; Sensfuss, S. Macromolecules 2006, 39, 7844-7853.

28. Zhan, X.; Tan, Z.; Domercq, B.; An, Z.; Zhang, X.; Barlow, S.; Li, Y.; Zhu, D.; Kippelen, B.; Marder, S. R. J Am Chem Soc 2007, 129, 7246-7247.

29. Zhu, Y.; Champion, R. D.; Jenekhe, S. A. Macromolecules 2006, 39, 8712-8719.
30. Champion, R. D.; Cheng, K. F.; Pai, C. L.; Chen, W. C.; Jenekhe, S. A. Macromol Rapid Commun 2005, 26, 1835-1840.

31. Gebeyehu, D.; Pfeiffer, M.; Maennig, B.; Drechsel, J.; Werner, A.; Leo, K. Thin Solid Films 2004, 451-452, 29-32.

32. (a) Shin, R. Y. C.; Kietzke, T.; Sudhakar, S.; Chen, Z. K.; Dodabalapur, A.; Sellinger, A. Chem Mater 2007, 19, 1892-1894; (b) Kietzke, T.; Shin, R. Y. C.; Egbe, D. A. M.; Chen, Z. K.; Sellinger, A. Macromolecules 2007, 40, 4424-4428; (c) Ooi, Z. E.; Tam, T. L.; Shin, R. Y. C.; Chen, Z. K.; Kietzke, T.; Sellinger, A.; Baumgarten, M.; Mullene, K.; deMello, J. C. J Mater Chem 2008, 18, 46194622; (d) Mei, J.; Heston, N. C.; Vasilyeva, S. V.; Reynolds, J. R. Macromolecules 2009, 42, 14821487.

33. (a) Fan, B.; Hany, R.; Moser, J. E.; Nüesch, F. Org Electron 2008, 9, 85-94; (b) Belcher, W. J.; Wagner, K. I.; Dastoor, P. C. Sol Energy Mater Sol Cells 2007, 91, 447-452; (c) Suresh, P.; Balaraju, P.; Sharma, S. K.; Roy, M. S.; Sharma, G. D. Sol Energy Mater Sol Cells 2008, 92, 900-908; (d) Wang, M.; Wang, X. Sol Energy Mater Sol Cells 2007, 91, 1782-1787.

34. (a) Wang, M.; Wang, X. Sol Energy Mater Sol Cells 2008, 92, 766-771; (b) Castro, F. A.; Faes, A.; Geiger, T.; Graeff, C. F. O.; Nagel, M.; Nüesch, F.; Hany, R. Synth Metal 2005, 155, 51-55; (c) Guo, X.; Bu, L.; Zhao, Y.; Xie, Z.; Geng, Y.; Wang, L. Thin Solid Films 2009, 517, 4654-4657; (d) Bouclé, J.; Chyla, S.; Shaffer, M. S. P.; Durrant, J. R.; Bradley, D. D. C.; Nelson, J. Adv Funct Mater 2008, 18, 622-633.

35. (a) van Mullekom, H. A. M.; Vekemans, J. A. J. M.; Havinga, E. E.; Meijer, E. W. Mater Sci Eng 2001, 32, 1-40; (b) Lim, Y. F.; Shu, Y.; Parkin, S. R.; Anthony, J. E.; Malliaras, G. G. J Mater Chem 2009, 19, 3049-3056; (c) Roquet, S.; Cravino, A.; Leriche, P.; Alévêque, O.; Frère, P.; Roncali, J. J Am Chem Soc 2006, 128, 3459-3466; (d) Yasuda, T.; Imase, T.; Nakamura, Y.; Yamamoto, T. Macromolecules 2005, 38, 4687-4697; (e) Zhang, Z. G.; Zhang, K. L.; Liu, G.; Zhu, C. X.; Neoh, K. G.; Kang, E. T. Macromolecules 2009, 42, 3104-3111; (f) Li, K. C.; Hsu, Y. C.; Lin, J. T.; Yang, C. C.; Wei, K. H.; Lin, H. C. J Polym Sci Part A: Polym Chem 2008, 46, 4285-4304; (g) Li, K. C.; Hsu, Y. C.; Lin, J. T.; Yang, C. C.; Wei, K. H.; Lin, H. C. J Polym Sci Part A: Polym Chem 2009, 47, 20732092; (h) Li, K. C.; Huang, J. H.; Hsu, Y. C.; Huang, P. J.; Chu, C. W.; Lin, J. T.; Ho, K. C.; Wei, K. H.; Lin, H. C. Macromolecules 2009, 42, 3681-3693.

36. Shen, Z.; Strauss, J.; Daub, J. Chem Commun 2002, 5, 460-461.

37. Lai, R. Y.; Kong, X.; Jenekhe, S. A.; Bard, A. J. J Am Chem Soc 2003, 125, 12631-12639. 
38. Liu, Y.; Cao, H.; Li, J.; Chen, Z.; Cao, S.; Xiao, L.; $\mathrm{Xu}$, S.; Gong, Q. J Polym Sci Part A: Polym Chem 2007, 45, 4867-4878.

39. Yang, L. Y.; Wang, C.; Li, L. Q.; Janietz, S.; Wedel, A.; Hua, Y. L.; Yin, S. G. J Polym Sci Part A: Polym Chem 2007, 45, 4291-4299.

40. Cho, N. S.; Park, J. H.; Lee, S. K.; Lee, J.; Shim, H. K. Macromolecules 2006, 39, 177-183.

41. Tang, W.; Kietzke, T.; Vemulamada, P.; Chen, Z. K. J Polym Sci Part A: Polym Chem 2007, 45, 5266-5276.

42. Zou, Y.; Wu, W.; Sang, G.; Yang, Y.; Liu, Y.; Li, Y. Macromolecules 2007, 40, 7231-7237.

43. Roncali, J. Chem Rev 1997, 97, 173-206.

44. Tu, G.; Li, H.; Forster, M.; Heiderhoff, R.; Balk, L. J.; Scherf, U. Macromolecules 2006, 39, 43274331.

45. (a) Velusamy, M.; Thomas, K. R. J.; Lin, J. T.; Hsu, Y. C.; Ho, K. C. Org Lett 2005, 7, 18991902; (b) Thomas, K. R. J.; Hsu, Y. C.; Lin, J. T.; Lee, K. M.; Ho, K. C.; Lai, C. H.; Cheng, Y. M.; Chou, P. T. Chem Mater 2008, 20, 1830-1840; (c) Tsai, M. S.; Hsu, Y. C.; Lin, J. T.; Chen, H. C.; Hsu, C. P. J Phys Chem C 2007, 111, 1878518793; (d) Thomas, K. R. J.; Lin, J. T.; Hsu, Y. C.; Ho, K. C. Chem Commun 2005, 4098-4100; (e) Lin, J. T.; Chen, P. C.; Yen, Y. S.; Hsu, Y. C.; Chou, H. H.; Yeh, M. C. P. Org Lett 2009, 11, 97100.

46. (a) Koumura, N.; Wang, Z. S.; Mori, S.; Miyashita, M.; Suzuki, E.; Hara, K. J Am Chem Soc 2006, 128, 14256-14257; (b) Wang, Z. S.; Koumura, N.; Cui, Y.; Takahashi, M.; Sekiguchi, H.; Mori, A.; Kubo, T.; Furube, A.; Hara, K. Chem Mater 2008, 20, 3993-4003; (c) Kim, J. J.; Choi, H.; Lee, J. W.; Kang, M. S.; Song, K.; Kang, S. O.; Ko, J. J Mater Chem 2008, 18, 5223-5229; (d) Wang, Z. S.; Cui,
Y.; Dan-oh, Y.; Kasada, C.; Shinpo, A.; Hara, K. J Phys Chem C 2007, 111, 7224-7230.

47. Lin, H. C.; Tsai, C. M.; Huang, G. H.; Tao, Y. T. Macromolecules 2006, 39, 557-568.

48. Wu, C. W.; Lin, H. C. Macromolecules 2006, 39, 7985-7997.

49. Lin, H. C.; Jiang, M. D.; Wu, S. C.; Jou, L. L.; Chou, K. P.; Huang, C. M.; Wei, K. H. J Polym Sci Part A: Polym Chem 2009, 47, 4685-4702.

50. Liang, T. C.; Lin, H. C. J Polym Sci Part A: Polym Chem 2009, 47, 2734-2753.

51. Yang, P. J.; Wu, C. W.; Sahu, D.; Lin, H. C. Macromolecules 2008, 41, 9692-9703.

52. Chen, C. P.; Chan, S. H.; Chao, T. C.; Ting, C.; Ko, B. T. J Am Chem Soc 2008, 130, 1282812833

53. Lee, J. Y.; Painter, P. C.; Coleman, M. M. Macromolecules 1988, 21, 954-960.

54. Roncali, J. Macromol Rapid Commun 2007, 28, 1761-1775.

55. Huo, L.; Tan, Z.; Wang, X.; Zhou, Y.; Han, M. F.; Li, Y. F. J Polym Sci Part A: Polym Chem 2008, 46, 4038-4049.

56. Morteani, A. C.; Sreearunothai, P.; Herz, L. M.; Friend, R. H.; Silva, C. Phys Rev Lett 2004, 92, 247402-247404.

57. (a) Scharber, M. C.; Mühlbacher, D.; Koppe, M.; Denk, P.; Waldauf, C.; Heeger, A. J.; Brabec, C. J. Adv Mater 2006, 18, 789-794; (b) Brabec, C. J.; Cravino, A.; Meissner, D.; Sariciftci, N. S.; Fromherz, T.; Rispens, M. T.; Sanchez, L.; Hummelen, J. C. Adv Funct Mater 2001, 11, 374-380.

58. Baek, N. S.; Hau, S. K.; Yip, H. L.; Acton, O.; Chen, K. S.; Jen, A. K. Y. Chem Mater 2008, 20, 5734-5736.

59. Huang, J. H.; Ho, Z. Y.; Kekuda, D.; Chang, Y.; Chu, C. W.; Ho, K. C. Nanotechnology 2009, 20, 025202. 